\title{
EL PENSAMIENTO DE JUAN EGAÑA Y EL MONUMENTO ERIGIDO PARA CELEBRAR EL 18 DE SEPTIEMBRE DE 1819
}

\author{
EGAÑA'S THINKING AND THE MONUMENT THAT \\ WAS ERECTED TO CELEBRATE SEPTEMBER 18, 1819
}

\section{FERNANDO GUZMÁN SCHIAPPACASSE*}

\section{RESUMEN}

El año 1819 la Municipalidad de Santiago erigió un monumento para celebrar el primer aniversario de la Independencia, cuya estructura ocupaba toda la Plaza de Armas. La complejidad del programa iconográfico, compuesto por ocho esculturas, además de portales, columnas y balaustradas, permite suponer que su definición obedeció a un propósito político bien definido. El discurso contenido en el monumento posee una clara sintonía con el pensamiento moralista de Juan Egaña, quien concebía el ejercicio individual de las virtudes como el fundamento de la vida social. El presente trabajo se propone comparar el ideario político de Juan Egaña ${ }^{1}$ con el discurso visual del monumento erigido por la Municipalidad en 1819.

Palabras clave: Arte, monumento, Independencia.

\section{ABSTRACT}

In 1819 the city of Santiago built a monument to celebrate the first anniversary of Chilean Independence. The structure occupied the entire main square and had eight sculptures as well as imposing gateways, columns, balustrades and triumphal arcs. The complexity of the iconographic program suggests a relationship between the different symbols used and a specific political purpose. The discourse contained in the monument

* Doctor en Historia del Arte, profesor de la Universidad Adolfo Ibáñez. Santiago, Chile. Correo: fernando.guzman@uai.cl

${ }^{1}$ La extensión de la obra escrita de Egaña obligó a circunscribir el trabajo a aquellos textos que se consideraron de mayor relevancia para el propósito definido. Se consultaron: el Discurso sobre el método de educación nacional, que se conserva en el Archivo Nacional, escritos antes de 1813; las Cartas pehuenches, publicadas en 1819; la "Constitución Política del Estado de Chile" y 
was in tune with Egaña's moralistic thought which conceived the individual exercise of virtue as the basis for social life. The present paper offers a comparison between Egaña's political ideology and the visual discourse of the monument built by the city in 1819 .

Keywords: Art, monument, Independence.

Recibido: 29.04.11. Aceptado: 05.11.11.

\section{INTRODUCCIÓN}

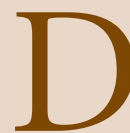

URANTE LA PRIMERA MITAD del siglo XIX era habitual en América y en Europa observar la persistencia de la tradición barroca de realizar monumentos efímeros para dar realce a fiestas de carácter civil o religioso $^{2}$. La idea de cautivar a la población con una arquitectura sorprendente y proponerle un complejo repertorio iconográfico es un legado de la cultura barroca que la mentalidad ilustrada parece haber recibido con beneplácito. Sin duda que estas estructuras decimonónicas se levantan de acuerdo a nuevos criterios estéticos y remitiéndose a un repertorio simbólico que no siempre coincide con el de los siglos anteriores (Voionmaa, 2004: 57-58).

En América, el comienzo de los procesos de emancipación produjo una adaptación de los rituales festivos coloniales a las nuevas necesidades expresivas (Peralta, 2007: 89), proceso en que se podría evidenciar la influencia de las formas festivas de la Revolución Francesa ${ }^{3}$. Para el caso chileno conta-

el "Examen instructivo de la Constitución Política de Chile promulgada en 1823", ambos textos en la versión contenida en la Colección de algunos escritos politicos, morales, poéticos y filosóficos, publicado en Londres entre 1826 y 1830; el texto Ocios filosóficos y poéticos en la quinta de las delicias, publicado en Londres en 1829, y el "Código Moral”, contenido en la Colección de algunos escritos políticos, morales, poéticos y filosóficos, publicados en Burdeos en 1831.

${ }^{2}$ Sobre este punto se puede consultar el trabajo de Isabel Cruz (1995: 296-307). Un ejemplo colombiano anterior a la Independencia se puede ver en la publicación de Ramón Gutiérrez y Rodrigo Gutiérrez (2006: 70-71). Para el caso rioplatense se puede revisar el artículo preparado por Burucúa, Jauregui, Malosetti y Munilla (1990).

${ }^{3}$ Se trata de un aspecto sobre el que habría que trabajar. No se puede desconocer la influencia de las formas festivas revolucionarias; sin embargo, se debe tener en cuenta que la arquitectura efímera o festiva estaba evolucionando en toda Europa, no sólo en Francia; de modo que las formas españolas o italianas también pudieron influir, en algún modo, en la concepción de los monumentos efímeros erigidos luego de iniciado el proceso de emancipación de Hispanoamérica. Para los monumentos efímeros levantados en Europa y América en la segunda mitad del siglo XVIII se puede consultar a Gabriel Guarda (1997: 227-237). Para conocer los cambios del monumento efímero en España se puede ver la publicación de Victoria Soto (1998). Para el caso italiano el trabajo de Fagiolo entrega un amplio catastro en que se pueden seguir las transformaciones que se operan entre el siglo XVIII y XIX (Fagiolo, 1997). Para el tema de la fiesta y la Revolución Francesa se puede ver el trabajo de Mona Ozouf (1976). 
mos con detalladas descripciones de las celebraciones de septiembre de 1812 (Talavera, 1812), de la declaración y jura de la Independencia en febrero de 1818 (Monteagudo, 1818) y de la fiesta de septiembre de ese mismo año, cuyos pormenores fueron recogidos en la edición del día 6 de noviembre del periódico El Sol de Chile. Sin embargo, el monumento efímero mejor descrito corresponde a la celebración del 18 de septiembre de 1819. En efecto, un artículo del periódico El Telégrafo, publicado el 9 de octubre de ese año, junto con reseñar el desarrollo de los festejos entrega una detallada caracterización de la estructura que la Municipalidad de Santiago levantó en la Plaza de Armas, espacio privilegiado de las fiestas cívicas (Peralta, 2007: 96).

La Ilustre Municipalidad de Santiago, animada del patriotismo más laudable, dispuso y costeó todas las fiestas. Por su orden se formó en la Plaza Mayor un cuadro de cuatrocientas varas de circunferencia, rodeada de una hermosa balaustrada pintada imitando el jaspe e iluminada por dos mil trescientas luces y de diez en diez varas sus remates respectivos. En cada esquina del cuadro había una portada de dos caras de ciento cuarenta y un varas de alto por el orden toscano; dos que miraban al oriente y las otras dos al occidente, con inscripciones alusivas a tan gran día. La que miraba a la esquina del Cabildo sostenía sobre su coronación una estatua que representaba al genio de la Victoria teniendo en una mano una cornucopia llena de coronas triunfales y en la otra una palma, armada de cota de malla. La que miraba hacia el portal sostenía igualmente sobre su coronación a la Abundancia que tenía en las manos una cornucopia llena de flores y frutos. En la tercera que miraba al Palacio del General San Martín, descansaba sobre su remate la Paz, sosteniendo en una mano un hacecillo de doradas mieses y en la otra una tea ardiendo con que incendiaba los instrumentos de la guerra. En la cuarta que estaba frente al Palacio Directorial, se miraba sobre su coronación el genio de la América, representado por un indio vestido según la costumbre de los naturales, armado de arco y aljaba y empuñando con su derecha una gran maza... En el centro del cuadro se elevaba un tabladillo de cincuenta varas de circunferencia rodeada de una balaustrada de lapislázuli, iluminada con cuarenta lámparas doradas y en sus intermedios quinientas luces; adornando cuatro columnas de jaspe rojo por orden dórico que sostenían sobre sus capiteles las estatuas de la Prudencia, Justicia, Fortaleza y Templanza (El Telégrafo, $\mathrm{N}^{\circ}$ 39, Santiago 8 de octubre de 1819, 4-6) 4 .

\footnotetext{
${ }^{4}$ La delimitación de la plaza y la construcción de un tablado correspondería a un patrón de varios monumentos efímeros (Peralta, 2007: 96). De acuerdo a la descripción, entre los pórticos
} 
Se trata de una producción artística compleja que requirió la participación de escultores, carpinteros, pintores especialistas en imitar la calidad de las piedras, quizá incluso un arquitecto para proponer un monumento que siguiera un orden compuesto, de acuerdo a las indicaciones de algún tratadista como Vitrubio. Los profesionales estaban disponibles: el escultor Ambrosio Santelices, que había trabajado con los jesuitas y con Toesca, aún estaba activo (Pereira, 1965: 309-313). La técnica de imitar piedras nobles la habían aprendido los pintores locales de los jesuitas germanos que estuvieron activos entre 1718 y 1772 (Guzmán, 2009: 47-70). Y, finalmente, los arquitectos que continuaron la labor de Toesca: Atero, Caballero y Goycolea, se encontraban en plena actividad (Guarda, 1997: 284-294).

Sin embargo, más allá de la concurrencia de diversos oficios artísticos, el monumento descrito requirió de una planificación intelectual. La disposición de la estructura y, especialmente, la selección de las figuras alegóricas obligaría a pensar que una persona o una pequeña comisión definió un discurso político que debió materializarse en las esculturas que describe el artículo de El Telégrafo 5 .

En efecto, el programa iconográfico parece tener un propósito bien definido. Si bien no sería posible conocer con exactitud las ideas de quienes concibieron el monumento, se puede proponer, a partir de los emblemas y de su ubicación en la plaza, una hipótesis de interpretación. En primer lugar se describe al Genio de la Victoria que con su Cornucopia y sus coronas de laureles mira al edificio del Cabildo, queriendo indicar de este modo que el mérito de la Independencia recae en la ciudadanía y, podría agregarse, no sólo en quienes lideraron las campañas militares que culminaron en la derrota de las fuerzas realistas. En la esquina sur oriente la Abundancia portando cornucopia de flores y frutos parece recordar a los comerciantes de la ciudad la necesidad de restaurar la vitalidad de la dañada actividad económica. Luego,

se levantaron cuatro pirámides iluminadas y en el centro del tabladillo una columna coronada por un globo terráqueo, una estrella radiante y una tarjeta en la que se leía la palabra libertad. El periódico entrega otros detalles del monumento de la Plaza así como de los demás ornamentos o alegorías que se instalaron en la ciudad, destacando los 363 arcos triunfales con signos emblemáticos y la imagen de la libertad en la plaza del Consulado.

${ }^{5}$ La identificación del autor es una de las obsesiones propias de la historia del arte. Al respecto se puede leer un clásico como Conceptos fundamentales de la historia del arte de Wölfflin (1943: 1-17). En ocasiones, el resultado de este esfuerzo colabora a la comprensión de la obra, en otras oportunidades el antecedente se transforma en un dato de escasa relevancia. Para el caso que nos ocupa sería inconducente buscar al autor material, la ausencia física de la obra impide reconocer el oficio del artista. Por el contrario, la identidad del autor intelectual podría permitir una comprensión más precisa de las ideas políticas que dan coherencia al monumento. 
frente a la residencia de San Martín se ubica la figura de la Paz destruyendo con el fuego las armas de la guerra, presentándole al General el deseo de inaugurar una época en que el uso de la fuerza militar no sea necesaria. En la esquina norponiente se ubica la alegoría del genio de América, armado de arco y maza, emblema que pareciera querer proponer que el futuro de paz y prosperidad debe construirse a partir de las riquezas del continente y los valores de la población local. Finalmente, en el centro de la Plaza cuatro columnas sostienen las esculturas de las cuatro virtudes cardinales.

En consonancia con la visión de futuro que pareciera empapar la concepción del monumento, los comitentes parecieran querer recordar a los ciudadanos de Santiago que la patria necesita hombres prudentes, justos, fuertes y templados para lograr su plenitud. Sin embargo, a la luz de la disposición general del monumento, es posible interpretar las esculturas en otro sentido. La victoria sobre el enemigo, la abundancia, la paz y el genio local son las puertas que permitirán llegar a un estado en que los ciudadanos serán naturalmente virtuosos. Se trata de condiciones que antes no existían y que, por tanto, impedían el ejercicio de los buenos hábitos; en el futuro, el vicio se leerá como una esclavitud cuyas cadenas aún atenazan a quienes no han traspasado los cuatro portales descritos (Guzmán, 2010: 26).

Si bien la promoción de la vida virtuosa era función específica de las obras teatrales (Peralta, 2007: 117), no se debe descartar que dichos mensajes fueran reforzados, como pareciera ser el caso, por pinturas o esculturas alegóricas.

\section{EGAÑA AUTOR DEL MONUMENTO}

Las esculturas de la prudencia, la justicia, la fortaleza y la templanza pueden ser la clave para identificar al autor intelectual del monumento. Si el objetivo de los cuatro emblemas era proponer a los ciudadanos un camino de virtud que las circunstancias históricas favorecen y, a la vez, reclaman, se podría sospechar que Juan Egaña habría participado en la concepción del programa arquitectónico e iconográfico que el Municipio levantó para celebrar el aniversario de la denominada "regeneración política" (ANCH, Cabildo de Santiago, MFN 83, f. 6).

Mario Góngora en su artículo "El rasgo utópico en el pensamiento de Juan Egaña" afirma que para el autor limeño el ejercicio individual de las virtudes

es el fundamento de la vida republicana, si los ciudadanos no poseen el hábito 
de supeditar el interés particular al general la vida social se agostaría. El Estado debe concurrir activamente para crear las condiciones que permitan que el ciudadano ejercite la virtud republicana, aspecto en el que Egaña seguiría a autores como Rousseau o Mably (Góngora, 1964: 97). Walter Hanish sintetiza la forma como el autor concibe la manera de hacer realidad su principio, señalando que "hay dos grandes resortes para fomentar las virtudes cívicas y que constituyen toda la filosofía de la legislación: primero, transforma las virtudes en costumbres por medio de las instituciones públicas; segundo, vincular precisamente los premios y honores a las bellas acciones, siendo el único juez de esta aplicación la opinión pública" (Hanisch, 1964: 78). Vasco Castillo, por su parte, ha formulado el concepto de aristocracia cívica para explicar las ideas de Egaña en este punto, concluyendo que para el jurista "la república ha de ser gobernada por ciudadanos virtuosos, y éstos son los que se califica como los mejores" (Castillo, 2009: 129).

Egaña, en el Examen instructivo de la Constitución Política de Chile, se refiere a la crisis moral de Europa, sorprendiéndose de que en los pueblos de ese continente convivan el progreso cultural y de la ideas con el deterioro de las costumbres, concluye que "las luces, separadas de la probidad y las costumbres, son el don más funesto que puede presentarse a la débil humanidad" (Egaña, 1826-1830a: 96). En la Constitución de $1823^{6}$, redactada por Egaña, en el artículo 38 específicamente, se precisa que algunas de las atribuciones del Senado son vigilar la moral pública y las costumbres, manteniendo un catastro individualizado de las acciones virtuosas de cada ciudadano (Egaña, 1826-1830a: 15-16); voluntad de control social que se manifiesta aún con mayor nitidez en el Examen instructivo de la Constitución Política de Chile, concretamente cuando afirma: "Nuestra constitución dirige la moralidad del ciudadano desde su nacimiento hasta el último momento de su existencia" (Egaña, 1826-1830b: 187). Para cumplir cabalmente tan ambicioso cometido se requerían instrumentos adicionales; aspecto que aborda el artículo 249 de la carta fundamental al expresar la necesidad de contar con un código moral que forme parte de la legislación del Estado, sus normas estarían redactadas con el fin de orientar a los ciudadanos en las diversas circunstancias de la vida, estimulando la virtud y apartando del vicio (Egaña, 1826-1830a: 80); El "Código Moral" fue efectivamente redactado por Egaña y presentado para su aprobación el año 1823, sin embargo, no tuvo aplicación efectiva, siendo publicado más tarde en Francia el año 1831.

\footnotetext{
${ }^{6}$ La Constitución preparada por Egaña fue promulgada el 29 de diciembre de 1823 y derogada en enero de 1825 .
} 


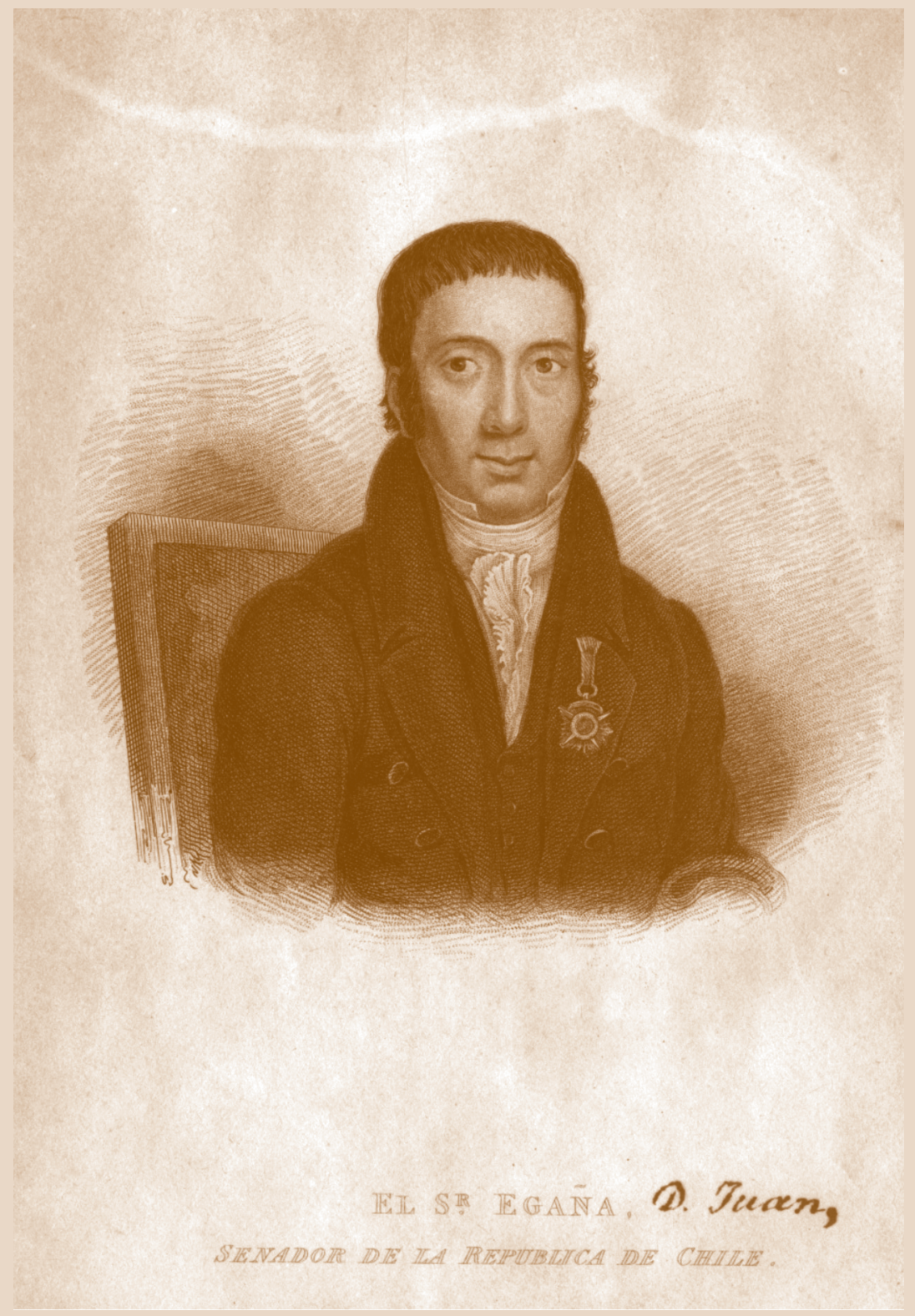

Juan Egaña. Grabado perteneciente a la colección del Museo Histórico Nacional. 
La moral y las costumbres cívicas deben estar para Egaña en el centro de una vida republicana. El ejercicio de las virtudes y la formación de una aristocracia cívica serían los antídotos que impedirían la corrupción de la democracia y el caudillismo militar (Castillo, 2009: 140). Las esculturas de las cuatro virtudes cardinales ubicadas sobre columnas y en el centro de la Plaza de Armas de Santiago parecen plasmar las ideas del intelectual. A la nueva sociedad se accede gracias a la Victoria sobre el enemigo, a la prosperidad del comercio, a la paz y la tranquilidad y a las riquezas de América. Pero, en el corazón de la vida republicana se encuentra el esfuerzo individual por alcanzar las virtudes de justicia, fortaleza y templanza que el Estado debe favorecer con un cuerpo de normas jurídicas, con distinciones y honores y, porque no señalar, con un repertorio de formas artísticas que oriente su actuar.

En este punto se debe agregar que Egaña considera de especial importancia las formas y colores como forjadoras de las costumbres, al mismo tiempo que deposita una especial confianza en las fiestas y rituales cívicos como medios para mover a la virtud (Góngora, 1964: 105-106). En las Cartas pehuenches expresa su preocupación por la carencia de vestimentas apropiadas para quienes detentan cargos públicos: "siendo tan necesaria en una revolución la pompa y el decoro, aún no se ha establecido un traje imponente que distinga a las autoridades" (Egaña, 1819: 10). En el mismo texto recomienda fomentar el entusiasmo cívico a través de fiestas que ensalcen la virtud y amonesten el egoísmo y el vicio (Egaña, 1819: 6). El artículo 258 de la Constitución del año 1823 establece cuatro fiestas cívicas: a la beneficencia, a la justicia, a la agricultura y las artes y a la gratitud nacional; señalando expresamente que deben estar "decoradas de toda la pompa exterior e incentivos heroicos posibles" (Egaña, 1826-1830a: 84-85).

Egaña manifiesta una y otra vez su confianza en los efectos benéficos de las formas sensibles, en particular de la arquitectura, las artes y la música. En el "Discurso sobre el método de Educación Nacional" recomienda que el edificio del Instituto Nacional sea "sólido y sencillo" representando así la felicidad pública (Fondo Varios, Vol. 796: foja 38r). En el mismo texto señala que la mejor forma de extirpar el vicio y mover a la virtud son las majestuosas ceremonias, las representaciones, los discursos elocuentes y la música heroica (Fondo Varios, Vol. 796: fojas 26 y 28r). En su "Código Moral", presentado el año 1823, establece la ritualidad que debe acompañar a las fiestas de la beneficencia pública, la moralidad, la agricultura y las artes y la gratitud nacional, instituidas por la Constitución de 1823 en su artículo 258. Junto con detallar las vestimentas, los premios y otros aspectos rituales, se detiene a describir los monumentos que se deben erigir para cada ocasión. Para conmemorar la batalla de Maipú o fiesta de la moralidad se ordena construir un "magnífico 
teatro, o semicírculo formado en la plaza, cuyo frente principal ocupará un gran trono, en donde se colocará la estatua de la justicia ricamente adornada" (Egaña, 1831: 128-129), en las gradas del trono se deben ubicar esculturas de Isaac postrado ante Abraham, la de Bruto condenando a sus hijos, Leonidas en el paso de las Termópilas y Sócrates tomando la cicuta. Para el 18 de septiembre o fiesta de la agricultura y la industria se ordena levantar arcos florales y erigir "un magnífico altar, donde se halle colocada la representación del Ser Supremo, con los símbolos del criador y conservador" (Egaña, 1831: 134-135), también se estipula la presencia de estatuas de la Paz y la Justicia. Las normas del Código no tuvieron aplicación efectiva y, por tanto, se puede suponer que las alegorías escultóricas descritas no fueron erigidas. Además de estos conjuntos alegóricos establecidos en el "Código Moral", se conoce el proyecto -no ejecutado- de un monumento permanente para conmemorar la promulgación de la Constitución de 1823; efectivamente, el decreto de diciembre de 1829, firmado por Egaña y Ramón Freire, ordenaba la erección de un arco triunfal de mármol; el texto describe la escultura que se debía poner en su cúspide y las leyendas que debían inscribirse en sus fachadas (Voionmaa, 2004: 80-82). Su visión sobre la educación, la relevancia que le asigna en el "Código Moral" a la descripción de los conjuntos escultóricos que se debían erigir para las fiestas cívicas y la atención que se le presta al proyecto de arco triunfal reflejan el hondo interés del jurista en asuntos de carácter artístico y su confianza en la influencia que los emblemas tendrían en el comportamiento de los ciudadanos (Guzmán y Yáñez, 2013).

Todo lo anterior permite afirmar que Egaña habría considerado un deber de especial relevancia tomar a su cargo la programación de una fiesta cívica y particularmente la concepción de un monumento efímero que destacara los valores y virtudes republicanos. Para él la decisión de las formas arquitectónicas, la elección de los colores de las estructuras y muy particularmente la formación del programa iconográfico no sería un asunto intrascendente, ni una preocupación puramente estética, en cada aspecto se jugaría una posibilidad de inculcar en los ciudadanos la conveniencia personal y colectiva de llevar una vida adecuada a ciertas normas morales ${ }^{7}$. Se podría decir que para Egaña la responsabilidad de dirigir las obras del monumento efímero para la fiesta del 18 de septiembre de 1819 era una labor semejante, al menos en sus efectos, a redactar los artículos de la Constitución o de un código moral.

${ }^{7}$ En este aspecto se puede observar la sintonía de Egaña con la concepción marcadamente didáctica que tuvieron los monumentos efímeros levantados durante la Revolución Francesa (Ozouf, 1976: 335). 


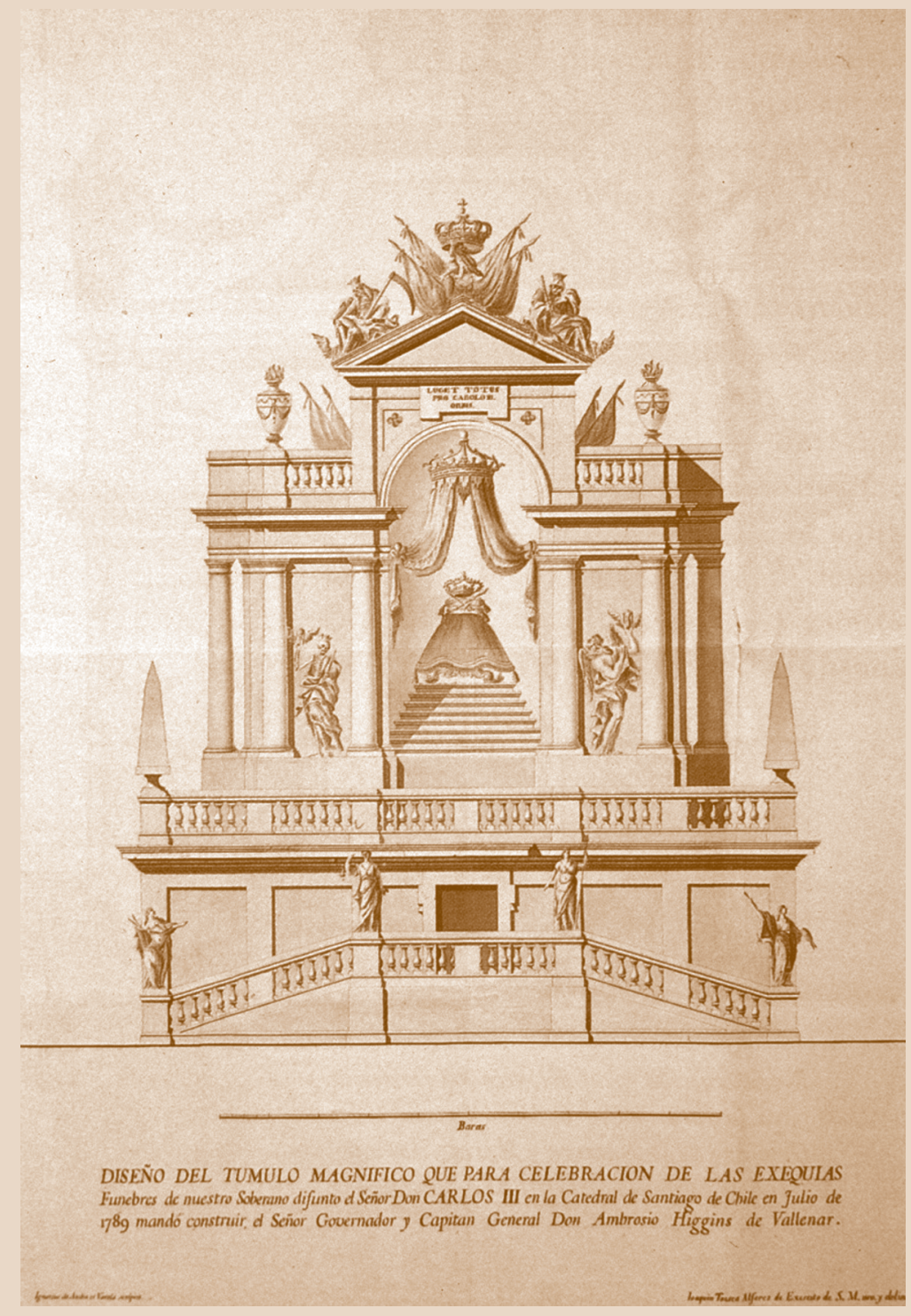

Túmulo funerario diseñado por Joaquín Toesca para las exequias de Carlos III en 1789. El hecho, bien probable, de que un discípulo del arquitecto romano haya levantado el monumento efímero de 1819, permite pensar que ambas soluciones arquitectónicas fueron semejantes. La descripción de El Telégrafo menciona elementos presentes en este dibujo que se conserva en el Archivo de Indias en Sevilla: columnas de orden dórico, balaustradas, pirámides y esculturas alegóricas. 
Junto a estos aspectos que permiten fundar la posibilidad de que Egaña sea el inspirador del monumento de 1819 -su concepción de la moral como el fundamento de la vida cívica y su aprecio por la pompa y las fiestas cívicas- se deben tener en cuenta sus vinculaciones con la Municipalidad de Santiago.

En las actas del Cabildo de Santiago no se encuentra una referencia precisa al monumento ${ }^{8}$, sólo queda constancia, en una anotación del 24 de septiembre, de las dificultades que existían para financiar los diversos aspectos de la fiesta: "por disposición del Supremo Gobierno se ha establecido que la fiesta del diez y ocho de septiembre sea propia del Cabildo, costeada con los fondos y rentas de la ciudad, no obstante de haberse representado por medio de una diputación la escasez de propio que con dificultad cubrían las cargas que tuvieron en el día" (MFN 83. Actas del Cabildo de Santiago. 24 de septiembre de 1819: foja 16). Tampoco se identifica a la persona que se hizo responsable de definir las características de la celebración que, a petición del gobierno, debía incluir al menos un baile conmemorativo (MFN 83. Actas del Cabildo de Santiago. 24 de septiembre de 1819: foja 16r). El único antecedente disponible sería la nómina de los alcaldes y regidores que estuvieron en funciones durante ese año.

El $1^{\circ}$ de enero de 1819 , como era habitual, se desarrolló la elección de las nuevas autoridades municipales. El acta que recoge los resultados de la votación, luego de mencionar a los regidores que ya habían ejercido como tales el año 1818, entrega la nómina de los que se integraban al gobierno municipal, el segundo en la lista es el "Doctor don Juan Egaña" como se lo identifica en el acta (MFN 83. Actas del Cabildo de Santiago. 1 de enero de 1819: foja 6). Todo parece indicar que ejerció el cargo de regidor durante todo el año 1819. $\mathrm{Al}$ año siguiente, 1820 , no postuló al cargo o no salió electo, pues su nombre no aparece en la nómina correspondiente. Lo cierto es que para septiembre de 1819 Egaña era regidor de la Municipalidad de Santiago, lo que le permitió participar de las discusiones que definieron los diversos aspectos de la celebración del dieciocho. La sofisticación iconográfica del conjunto monumental levantado por la Municipalidad obliga a pensar que su autor intelectual fue un hombre erudito que confiaba en el efecto benéfico que las formas arquitectónicas y las representaciones artísticas pueden ejercer en la población. Es probable que uno de los regidores en ejercicio recibiera la responsabilidad

\footnotetext{
${ }^{8}$ Es probable que las autoridades de la ciudad hayan solicitado la colaboración de los gremios para financiar el monumento, como se hacía para levantar los altares de la fiesta del Corpus Christi (Cruz, 1995: 208); en caso de haber procedido de esta forma, la Municipalidad no habría incurrido en gastos y, por tanto, la documentación administrativa no tendría por qué reflejar lo realizado.
} 
de coordinar los festejos, al menos podemos sospechar que Egaña demostraría un gran interés por asumir esta labor.

Los antecedentes recabados permiten postular, con gran seguridad, que Juan Egaña pudo ser el autor intelectual del monumento efímero levantado por la Municipalidad de Santiago para conmemorar el 18 de septiembre de 1819. Sin embargo, lo más significativo no es la identificación del autor, sino el reconocimiento de que detrás de una serie de elementos ornamentales hay una concepción ideológica precisa y una noción de la función que pueden jugar el arte y la arquitectura en la vida social ${ }^{9}$.

El estudio de los monumentos efímeros erigidos o concebidos durante las primeras décadas del siglo XIX es una tarea por realizar. La comprensión de la forma precisa en que el lenguaje barroco de las grandes máquinas temporales fue adaptado y transformado, tanto en Chile como en Latinoamérica, para servir a la lógica del proceso de independencia y de la vida republicana podría arrojar luces de gran interés sobre el período.

\section{REFERENCIAS}

ANCH, Actas del Cabildo de Santiago, MFN 83.

Burucúa, J. E.; Jauregui, M.; Malosetti, L.; Munilla, M. L. (1990). "Influencia de los tipos iconográficos de la revolución francesa en los países del plata". Cahiers des Amériques Latines, L'Amérique Latine face à la révolution 10, 147-157.

Castillo, V. (2009). La creación de la República. La filosofía pública en Chile 1810-1830. Santiago, Chile: Lom ediciones.

Cruz, I. (1995). La fiesta, metamorfosis de lo cotidiano. Santiago, Chile: Ediciones Universidad Católica de Chile.

Egaña, J. (1819). Cartas pehuenches o correspondencia de dos indios naturales del Pire-Mapu, el uno residente en Santiago y el otro en las Cordilleras Pehuenches. Santiago, Chile: Imprenta del Gobierno.

. (1826-1830a). "Constitución Política del Estado de Chile". Colección de algunos escritos políticos, morales, poéticos y filosóficos. Londres, Inglaterra.

. (1826-1830b). "Examen instructivo de la Constitución Política de Chile promulgada en 1823". Colección de algunos escritos políticos, morales, poéti$\cos y$ filosóficos. Londres, Inglaterra.

\footnotetext{
${ }^{9}$ Se abre en este punto una línea de reflexión que supera los alcances del presente trabajo, pero que resulta indispensable para alcanzar una comprensión plena de la lógica que empapa la concepción del monumento: rastrear en los autores de la antigüedad clásica y en los pensadores ilustrados los fundamentos precisos que llevaron a Egaña a concebir, de una manera determinada, las relaciones entre el arte y la sociedad.
} 
. (1829). Ocios filosóficos y poéticos en la quinta de las delicias. Londres, Inglaterra.

. (1831). "Código Moral". Colección de algunos escritos políticos, morales, poéticos y filosóficos. Burdeos, Francia: Imprenta de Laplace y Beaume.

. (s/f). Discurso sobre el método de educación nacional. Fondo Varios, Vol. 796.

El Sol de Chile, No 18, Santiago, 6 de noviembre de 1818, 7.

El Telégrafo, $\mathrm{N}^{\circ} 39$, Santiago 8 de octubre de 1819, 4-6.

Fagiolo, M. (1997). La Festa a Roma. Dal Rinascimiento al 1870. Roma, Italia: Humberto Allemadi y Cia.

Góngora, M. (1964). "El rasgo utópico en el pensamiento de Juan Egana”. Anales de la Universidad de Chile, CXXII, 129, 93-119.

Guarda, G. (1997). El arquitecto de La Moneda. Joaquín Toesca, 1752-1799. Santiago: Ediciones Universidad Católica de Chile.

Gutiérrez, R. y Gutiérrez, R. (2006). América y España, imágenes para una historia. Madrid, España: Fundación Mapfre.

Guzmán, F. (2009). Representaciones del paraíso. Retablos en Chile, siglos XVIII $y$ XIX. Santiago, Chile: Editorial Universitaria. . (2010). "Un monumento efímero para celebrar la Independencia". Guzmán, F. y Martínez J. M. (Editores), Arte americano e Independencia. Nuevas Iconografias. Quintas Jornadas de Historia del Arte. Santiago, Chile: Museo Histórico Nacional, Universidad Adolfo Ibáñez, Centro de Restauración, Conservación y Estudios Artísticos CREA.

Guzmán, F. y Yáñez, E. (2013). “La recepción de los clásicos en las concepciones de Juan Egaña acerca del arte”. Alpha 37, 135-148.

Hanisch, W. (1964). La filosofía de don Juan Egaña. Santiago: Ediciones Historia.

Monteagudo, B. (1818). Relación de la gran fiesta cívica celebrada en Chile el 12 de febrero de 1818. Santiago, Chile: Imprenta del Estado.

Ozouf, M. (1976). La fête révolutionnaire: 1789-1799. París, Francia: Gallimard.

Peralta, P. (2007). Chile tiene fiesta. El origen del 18 de septiembre (1810-1937). Santiago, Chile: Lom ediciones.

Pereira Salas, E. (1965). Historia del Arte en el Reino de Chile. Santiago, Santiago, Chile: Ediciones de la Universidad de Chile.

Soto, V. (1998). "Los catafalcos de Carlos III: entre la influencia neoclásica y la herencia del barroco". Fragmentos: Revista de Arte 12, 13 y 14, 129-143.

Talavera, M. A. [1812] (1900-1966). "Revoluciones de Chile". Colección de Historiadores y documentos relativos a la Independencia de Chile XXIX, 645-652.

Voionmaa, L. F. (2004). Escultura pública. Del monumento conmemorativo a la escultura pública. Santiago 1792-2004. Santiago, Chile: Ocho Libros Editores.

Wölfflin, E. (1943). Conceptos fundamentales de la historia del arte. Madrid, España: Espasa Calpe. 